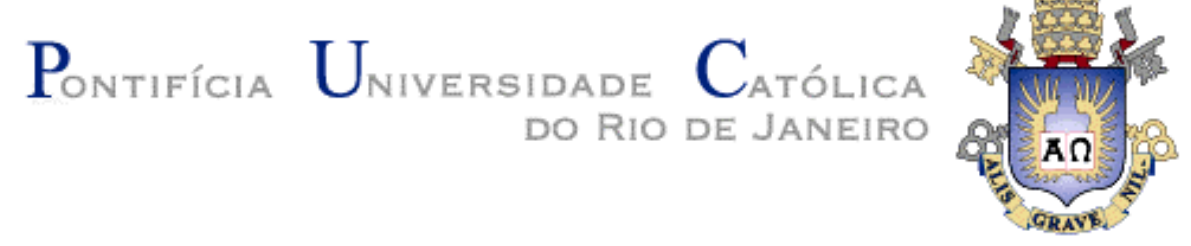

Luis Eduardo Formigheri

Comportamento de um Aterro Sobre Argila Mole da Baixada Fluminense

Dissertação de Mestrado

Dissertação apresentada ao Departamento de Engenharia Civil da PUC-Rio como parte dos requisitos para obtenção do título de Mestre em Ciências de Engenharia Civil: Geotecnia.

Orientadores: $\quad$ Alberto S. F. J. Sayão Denise M. S. Gerscovich

Rio de Janeiro

Agosto de 2003 


\section{Luis Eduardo Formigheri}

Comportamento de um Aterro Sobre Argila Mole da Baixada Fluminense

Dissertação apresentada como requisito parcial para obtenção do título de Mestre pelo Programa de Pós-Graduação em Engenharia Civil do Departamento de Engenharia Civil do Centro Técnico Científico da PUC-Rio. Aprovada pela Comissão Examinadora abaixo assinada.

Prof. Alberto S.F. Jardim Sayão

Orientador

Departamento de Engenharia Civil - PUC-Rio

Profa. Denise Maria S. Gerscovich

Co-Orientador

UERJ

Prof. José Alberto R. Ortigão

UFRJ

Profa. Anna Laura L. S. Nunes COPPE/UFRJ

Prof. Ney Augusto Dumont Coordenador Setorial do Centro Técnico Científico - PUC-Rio

Rio de Janeiro, 28 de Agosto de 2003 
Todos os direitos reservados. É proibida a reprodução total ou parcial do trabalho sem autorização do autor, do orientador e da universidade.

\section{Luis Eduardo Formigheri}

Graduou-se em Engenharia Civil, pela Universidade de Passo Fundo, em janeiro de 2001. Trabalhou como engenheiro estagiário de obras em Passo Fundo. Ingressou no curso de mestrado em Engenharia Civil da PUC-Rio no ano de 2001, atuando na área de Geotecnia Experimental.

Ficha Catalográfica

Formigheri, Luis Eduardo

Comportamento de um Aterro Sobre Argila Mole da Baixada Fluminense / Luis Eduardo Formigheri; orientadores: Alberto de Sampaio Ferraz Jardim Sayão; Denise Maria Soares Gerscovich. - Rio de Janeiro: PUC, Departamento de Engenharia Civil, 2003.

[21]., 182 f.: il. ; 30,0 cm

1. Dissertação (mestrado) - Pontifícia Universidade Católica do Rio de Janeiro, Departamento de Engenharia Civil.

Inclui referências bibliográficas.

1. Engenharia Civil - Teses. 2. Ensaios de Campo. 3. Aterro sobre Argila Mole. 5. Recalque de Aterro. 6. Estabilidade de Aterro I. Sayão, Alberto S. F. J. (Alberto de Ferraz Jardim). II. Gerscovich, Denise Maria Soares. III. Pontifícia Universidade Católica do Rio de Janeiro. Departamento de Engenharia Civil. IV. Título. 
A meus amados pais Luiz Carlos e Inêz

e a minha noiva Maristâni 


\section{Agradecimentos}

\section{A Deus.}

Aos meus amados pais Luiz Carlos e Inêz, e irmãos Eliane, Luciane e Carlos Alberto, por sempre estarem ao meu lado e dividirem comigo alegrias e tristezas. Muito obrigado por acreditarem e me fazerem acreditar em meus sonhos.

À minha noiva Maristâni, a quem amo muito.

À minha segunda familia, Orly Tarcísio, Eroni, Mariane e Orly Matheus, pelo apoio e compreensão durante todo este tempo.

Ao meu orientador Alberto Sayão, pela sua amizade, ensinamentos e orientação na elaboração desta dissertação.

À minha orientadora Denise Gerscovich, pela sua amizade, paciência e pela determinação em tornar tudo possível. Muito obrigado por não me fazer desistir deste sonho.

Aos meus irmãos Alexandre Saré e Laryssa Petry Ligocki, pessoas especiais que dividiram sofrimentos e alegrias durante o período de mestrado.

Aos amigos Carlos Ataliba, Ana Júlia, Frederico, Patrícia, Lucas, Luciana, Nelly, Ciro, Roberta, Luciana Nunes e Jorge, pela ajuda, companhia e por tornarem dias difíceis em dias agradáveis e felizes.

À Ana Cristina, pelos conselhos e ensinamentos e acima de tudo paciência.

Aos funcionários do departamento, em especial a Ana Roxo, por ser uma grande amiga e conselheira.

Ao Professor J.A.R. Ortigão, pela disponibilização dos dados que possibilitaram a realização deste trabalho, além da pronta atenção as minhas dúvidas.

Aos funcionários da empresa Terratek, em especial ao amigo Carlos, pela gentileza e esclarecimentos prestados.

À CAPES, pela ajuda financeira indispensável ao desenvolvimento deste trabalho. 


\section{Resumo}

Formigheri, Luis Eduardo; Sayão, Alberto de Sampaio Ferraz Jardim; Gerscovich, Denise Maria Soares. Comportamento de um aterro sobre Argila Mole da Baixada Fluminense. Rio de Janeiro, 2003. 203p. Dissertação de Mestrado - Departamento de Engenharia Civil, Pontifícia Universidade Católica do Rio de Janeiro.

O comportamento de um aterro sobre argila mole da Baixada Fluminense foi estudado. Este aterro foi executado para a implantação da Indústria Rio Polímeros, com 3 metros de espessura, assente sobre um colchão drenante. Antes da construção, a área foi coberta com uma manta de geotêxtil. Para acelerar os recalques do aterro, geodrenos foram instalados na argila mole. $O$ aterro foi instrumentado com inclinômetros, placas de recalque e piezômetros. Durante a construção, foram observadas rupturas em áreas localizadas do aterro. Ensaios de palheta e piezocone foram realizados em diferentes etapas da obra. A resistência não drenada (Su) nos ensaios de palheta apresentaram-se dentro dos valores reportados em trabalhos anteriores. Nos ensaios de piezocone, Su apresentou um decréscimo com a profundidade. Os valores de OCR, estimados com o piezocone, situaram-se entre 1,5 e 3,0. O comportamento do aterro foi avaliado quanto a recalques e estabilidade. $O$ método de Asaoka permitiu uma estimativa satisfatória do coeficiente de adensamento e dos recalques. Os recalques estimados pela teoria de Terzaghi foram cerca de 2,5 vezes maiores do que os registrados no campo, devido a incertezas na compressibilidade da argila mole. O método de Asaoka indicou, para drenagem puramente vertical, um valor de $c_{v}$ cerca de 100 vezes maior que os valores de ensaios de laboratório e 2 vezes menor que os valores estimados para drenagem combinada e para ensaios de piezocone. A estabilidade do aterro foi avaliada em análises por equilíbrio limite. Os resultados confirmaram a existência de uma potencial instabilidade em algumas regiões do aterro.

\section{Palavras-chave}

Engenharia Civil, Ensaios de Campo, Aterro sobre Argila Mole, Recalque de Aterro, Estabilidade de Aterro. 


\section{Abstract}

Formigheri, Luis Eduardo; Sayão, Alberto de Sampaio Ferraz Jardim; Gerscovich, Denise Maria Soares. Behavior of an Embankment on a Soft Clay Deposit at Baixada Fluminense. Rio de Janeiro, 2003. 203p. MSc Thesis - Civil Engineering Department, Pontifícia Universidade Católica do Rio de Janeiro

The behavior of an embankment on a soft clay deposit at Baixada Fluminense was studied. This embankment was constructed for implantation of Rio Polimeros Industry. The embankment layer is $3 \mathrm{~m}$ thick and is placed over a layer of granular material. Before construction the entire area was covered with a geotextil. Geodrains were also installed to accelerate clay layer settlements. Some localized embankment failures were observed during construction. Vane and CPTU tests were performed at different construction stages. Values of undrained strength (Su), provided by vane tests, are in agreement with results reported in literature, for soft clay deposits at Baixada Fluminense. On the other hand, CPTU tests indicated a Su profile decreasing with depth. OCR values were estimated between 1.5 and 3.0. The performance of the embankment construction was evaluated with respect to its stability and settlement. The Asaoka's method allowed a suitable evaluation of both coefficient of consolidation and final settlements. However, settlements computed by Terzaghi's theory were about 2.5 times greater than monitored field values. These differences were attributed to uncertainties related to the clay layer compressibility parameters. The vertical coefficient of consolidation, computed with Asaoka's method, was 100 times greater than laboratory results and 2 times smaller than values estimated for combined consolidation and by CPTU data. The embankment stability was evaluated with limit equilibrium analyses. The results confirmed the occurrence of instability conditions at localized embankment areas.

\section{Keywords}

Civil Engineering, Field Tests, Embankment on Soft Clay, Embankment Settlement, Embankment Stability. 


\section{Sumário}

1. Introdução 22

2. Revisão Bibliográfica 24

2.1 Aterros sobre solos moles 24

2.2 Ensaios de campo 25

2.3 Instrumentação 33

2.4 Métodos de estimativa de recalque 36

2.5 Métodos de Previsão de Recalque 36

$\begin{array}{lll}2.5 .1 & \text { Teoria de adensamento } & 38\end{array}$

2.5.2 Aceleração de Recalques $\quad 40$

2.6 Interpretação de medidas de recalque 43

2.6.1 Método de Asaoka, (1978) modificado por Magnan e Deroy (1980) 43

2.6.2 Método de Orleach 45

$\begin{array}{lll}2.7 & \text { Análises de estabilidade } & 47\end{array}$

2.7.1 Reforço de aterros com geossintéticos 49

2.8 Casos históricos de aterros sobre solos moles 50

2.8.1 Aterro experimental sobre argila mole do Rio de Janeiro 50

2.8.2 Aeroporto Internacional Salgado Filho (Porto Alegre) 53

2.8.3 Estação de Tratamento de Esgoto (ETE) Alegria 55

2.8.4 Aterro sobre argila mole Senac/Sesc-Barra 58

3. Histórico do local 62

3.1 Descrição da Obra 62

3.2 Aspectos geológicos $\quad 65$

3.3 Aspectos geotécnicos $\quad 66$

$\begin{array}{lll}3.4 & \text { Ensaios de laboratório } & 67\end{array}$

$\begin{array}{lll}3.4 .1 & \text { Amostragem } & 67\end{array}$

$\begin{array}{lll}3.4 .2 & \text { Caracterização } & 70\end{array}$

$\begin{array}{lll}\text { 3.4.3 Permeabilidade } & 73\end{array}$

$\begin{array}{lll}3.4 .4 & \text { Adensamento } & 73\end{array}$

$\begin{array}{lll}3.4 .5 & \text { Resistência } & 76\end{array}$

$\begin{array}{ll}3.5 & \text { Ensaios de Campo }\end{array}$ 
$\begin{array}{lll}3.5 .1 & \text { Palheta } & 79\end{array}$

$\begin{array}{lll}3.5 .2 & \text { CPTU } & 81\end{array}$

3.5.3 Permeabilidade in-situ 81

3.6 Instrumentação de campo 82

3.6.1 Piezômetros 82

3.6.2 Inclinômetros 85

3.6.3 Placas de recalque 88

4. Análise dos Ensaios de Campo 90

$\begin{array}{lll}4.1 & \text { Ensaio de palheta } & 90\end{array}$

$\begin{array}{ll}4.2 & \text { Ensaio de piezocone }\end{array}$

$\begin{array}{lll}\text { 4.2.1 Parâmetros geotécnicos } & 102\end{array}$

5. Análise dos deslocamentos verticais 117

$\begin{array}{lll}5.1 & \text { Deslocamentos verticais } & 117\end{array}$

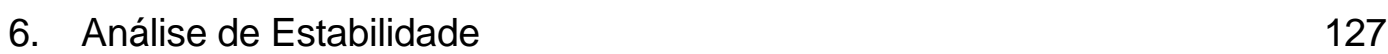

6.1 Descrição das áreas L, C e O 128

6.2 Parâmetros Geotécnicos 133

6.2.1 Aterro, colchão drenante e geossintético 133

6.2.2 Argila mole 134

6.3 Análise de estabilidade das áreas L, C e O 137

$\begin{array}{ll}\text { 7. Conclusões e Sugestões } & 140\end{array}$

$\begin{array}{ll}\text { 8. } & \text { Referências bibliográficas } \\ & 143\end{array}$

$\begin{array}{lr}\text { ANEXO } 1 & 150\end{array}$

Análises Químicas 151

Ensaios Triaxiais CIU e UU 152

Piezômetros Casagrande e Corda Vibrante 159

Placas de recalque 169

$\begin{array}{lr}\text { ANEXO } 2 & 179\end{array}$ 


\section{Lista de figuras}

Figura 1 - Aterro sobre solos moles (Dunniclif, 1993) 24

Figura 2 - Ensaios de palheta reportados por Collet (1978) 26

Figura 3 - Resultados dos ensaios de Palheta na argila do Rio de Janerio

(Ortigão \& Collet, 1986 apud Schnaid, 2000) 27

Figura 4 - Principais posições de instalação do elemento poroso 28

Figura 5 - Resultado típico do ensaio de dissipação de piezocone (Schnaid, 2000) 31

Figura 6 - Esquema de inclinômetro 35

Figura 7 - Evolução dos Recalques 37

Figura 8 - Disposição dos drenos $\quad 41$

Figura 9-Geometria dos drenos $\quad 41$

Figura 10 - Recalque no tempo pelo método de Asaoka (1978) 43

Figura 11 - Construção gráfica do método de Asaoka , modificado por Magnan e

Deroy (1980) 44

Figura 12 - Método de Orleach (Ferreira, 1991) 46

Figura 13 - Localização do aterro de Sarapuí (Ortigão 1983) 51

Figura 14 - Geometria do aterro Ortigão (1980) 51

Figura 15 - Fotos aéreas das obras no Aeroporto Internacional Salgado Filho 53

Figura 16 - Perfil esquemático do aterro AISF 54

Figura 17 - Distribuição dos drenos no AISF $\quad 54$

Figura 18 - Vista em planta do aterro da ETE Alegria, Spotti (2000) 57

Figura 19 - Foto aérea do aterro Sesc/Senac, na baixada de Jacarepaguá, RJ, Spotti (2000) 58

Figura 20 - Esquema da seção transversal do aterro, Spotti (2000) 59

Figura 21 - Mapa da localização do aterro 62

Figura 22 - Vista aérea do aterro em dois momentos da obra 63

Figura 23- Planta baixa esquemática do aterro 64

Figura 24 - Posição dos SPT's, dos perfis e espessura da argila mole (Terratek, 2002) 66

Figura 25 - Perfil de SPT - AA 68

Figura 26 - Perfis de SPT - BB 69

Figura 27 - Detalhe do amostrador tipo Osterberg 70 
Figura 28 - Valores dos limites de Atterberg $\quad 71$

Figura 29 - Variação do teor de M.O. com a profundidade 72

Figura 30- Variação de OCR, c c e c com a profundidade 74

Figura 31 - Valores de Cv - subáreas Tanques e Utilitários 75

Figura 32 - Valores de Cv - subáreas Etileno e Polietileno 75

Figura 33 - Valores de Cv - subáreas Parqueamento, Depósito e Prédios 76

Figura 34 - Trajetórias p’x q - subáreas Tanques e Utilitários 77

Figura 35 - Trajetórias p' x q - subáreas Etileno e Polietileno 77

Figura 36 - Trajetórias p' x q - subáreas Parqueamento, Depósito e Prédios 77

Figura 37 - Estado de tensões na ruptura - subáreas Tanques e Utilitários 78

Figura 38 - Estado de tensões na ruptura - subáreas Etileno e Polietileno 78

Figura 39 - Estado de tensões na ruptura - Parqueamento, Depósito e Prédios 79

Figura 40 - Ensaio de Palheta - Variações de (Su) indeformado com a profundidade

Figura 41 - Sensibilidade da argila $\quad 80$

Figura 42 - Localização dos ensaios CPTU 81

Figura 43 - Planta de localização dos piezômetros tipo Casagrande 83

Figura 44 - Planta de localização dos piezômetros tipo Corda Vibrante 84

Figura 45 - Excesso de poropressão no piezômetro CP-01 com o alteamento do aterro 84

Figura 46 - Excesso de poropressão no piezômetro VWP-01 com o alteamento de aterro $\quad 85$

Figura 47 - Planta de localização dos inclinômetros 86

Figura 48 - Instalação do I - $10 \quad 87$

Figura 49 - Leituras do inclinômetro $110 \quad 87$

Figura 50 - Deslocamento vertical com o alteamento do aterro no tempo 88

Figura 51 - Planta de localização das placas de recalque 89

Figura 52 - Divisão das áreas O, C e L 90

Figura 53 - Ensaios de palheta realizados na área $L \quad 91$

Figura 54 - Ensaios de palheta realizados na área C 92

Figura 55 - Ensaios de palheta na área O 92

Figura 56 - Perfil de resistência não drenada (Su) para área L 94

Figura 57 - Perfil de resistência não drenada (Su) para área C 95

Figura 58 - Perfil de resistência não drenada (Su) para área $\mathrm{O} 95$

Figura 59 - Perfis de resistência não drenada (Su) 96

Figura 60 - Ensaio CPTU 01 
Figura 61 - Ensaio CPTU $02 \quad 99$

Figura 62 - Ensaio CPTU $03 \quad 100$

Figura 63 - Ensaio CPTU $04 \quad 100$

Figura 64 - Ensaio CPTU $05 \quad 101$

Figura 65 - Ensaio CPTU $06 \quad 102$

Figura 66 - Perfil de resistência não drenada (Su) do ensaio CPTU $01 \quad 107$

Figura 67 - Perfil de resistência não drenada (Su) do ensaio CPTU 02107

Figura 68 - Perfil de resistência não drenada (Su) do ensaio CPTU 03108

Figura 69 - Perfil de resistência não drenada (Su) do ensaio CPTU 05109

Figura 70 - Perfil de resistência não drenada (Su) do ensaio CPTU $06 \quad 110$

Figura 71 - Curva de dissipação do ensaio CPTU 01 na argila mole 112

Figura 72 - Perfis de OCR para os ensaios CPTU 01, 02 e $03 \quad 115$

Figura 73 - Perfis de OCR para os ensaios CPTU 05 e 06

Figura 74 - Recalque x tempo x alteamento para placa PR - 07. 119

Figura 75 - Método de Asaoka PR - 07.

Figura 76 - Comparação de recalque (área L). 120

Figura 77 - Comparação de recalque (área C). 123

Figura 78 - Comparação de recalque (área O). 123

Figura 79 - Recalque x tempo x alteamento para placa PR - 04.

Figura 80 - Valores de $c_{v}$ em planta 126

Figura 81 - Localização das rupturas no aterro da industria Rio Polímeros 128

Figura 82 - Seção Transversal L1 na área L 129

Figura 83 - Seção transversal L3 na área L $\quad 129$

Figura 84 - Inclinômetro 108

Figura 85 - Seção transversal C na área C 131

Figura 86 - Inclinômetro $102 \quad 131$

Figura 87 - Inclinômetro $103 \quad 132$

Figura 88 - Seção transversal considerada para a área O 132

Figura 89 - Hipóteses (1, 2 e 3) para a área $L \quad 135$

Figura 90 - Hipóteses 1, 2, 3, 4 e 5 para área C 136

Figura 91 - Hipóteses 1, 2 e 3 para área $O \quad 137$

Figura 92 - Superfícies de ruptura para área C, ensaio de piezocone, hipótese 4

Figura 93 - Triaxial CIU - Área L 154

Figura 94 - Triaxial CIU Área L 154

Figura 95 - Triaxiais CIU - Área C 155 
Figura 96 - Triaxiais - Área C

Figura 97 - Triaxiais CIU - Área O 156

Figura 98 - Triaxiais CIU - Área O 156

Figura 99 - Triaxiais UU - Área L 157

Figura 100 - Triaxiais UU - Área C 157

Figura 101 - Triaxiais UU - Área O 158

Figura 102 - Piezômetro Casagrande - Área L 159

Figura 103 - Piezômetro Casagrande - Elevação do aterro no tempo - Área L 159

Figura 104 - Piezômetros Casagrande - Área C - Etileno 160

Figura 105 - Piezômetro Casagrande - Elevação do aterro no tempo - Área C Etileno 160

Figura 106 - Piezômetro Casagrande - Área C - Polietileno 161

Figura 107 - Piezômetro Casagrande - Elevação do aterro no tempo - Área C-

$\begin{array}{ll}\text { Polietileno } & 161\end{array}$

Figura 108 - Piezômetro Casagrande - Área O 162

Figura 109 - Piezômetro Casagrande - Elevação do aterro no tempo - Área O

Figura 110 - Anexo - Piezômetro Corda Vibrante - Variação de poropressão no tempo para Área L 163

Figura 111 - Anexo - Piezometro de Corda Vibrante - Elevação do aterro no tempo para Área $L \quad 164$

Figura 112 - Anexo - Piezômetro de Corda Vibrante para Área C 165

Figura 113 - Anexo - Piezômetro de Corda Vibrante - Elevação do aterro no tempo para área C 166

Figura 114 - Anexo - Piezômetros de Corda Vibrante para Área O 167

Figura 115 - Anexo - Piezômetro de Corda Vibrante - Elevação do aterro no tempo para área $O \quad 168$

Figura 116 - Placas de recalque - Área $L \quad 169$

Figura 117 - Placas de recalque - Área C 169

Figura 118 - Placas de recalque - Área O 170

Figura 119 - Placas de recalque - Área O. 170

Figura 120 - Ensaio de Dissipação do CPTU 01 na profundidade de 6,24 m 171

Figura 121 - Ensaio de Dissipação do CPTU 01 na profundidade de 10,30 m 171

Figura 122 - Ensaio de Dissipação do CPTU 01 na profundidade de 14,80 m 172

Figura 123 - Ensaio de Dissipação do CPTU 02 na profundidade de 5,07 m. 172

Figura 124 - Ensaio de Dissipação do CPTU 02 na profundidade de 11,27 m 173 
Figura 125 - Ensaio de Dissipação do CPTU 02 na profundidade de 14,45 m 173

Figura 126 - Ensaio de Dissipação do CPTU 03 na profundidade de 7,0 m 174

Figura 127 - Ensaio de Dissipação do CPTU 03 na profundidade de 9,0 m 174

Figura 128 - Ensaio de Dissipação do CPTU 03 na profundidade de 12,11 m 175

Figura 129 - Ensaio de Dissipação do CPTU 05 na profundidade de 4,0 m 175

Figura 130 - Ensaio de Dissipação do CPTU 05 na profundidade de 8,41m 176

Figura 131 - Ensaio de Dissipação do CPTU 05 na profundidade de 10,06 m 176

Figura 132 - Ensaio de Dissipação do CPTU 06 na profundidade de 4,27 m 177

Figura 133 - Ensaio de Dissipação do CPTU 06 na profundidade de 8,31 m 177

Figura 134 - Ensaio de Dissipação do CPTU 06 na profundidade de 12,35 m 178

Figura 135 - Placa de recalque RP - 06.

Figura 136 - Placa de recalque RP - $07 . \quad 181$

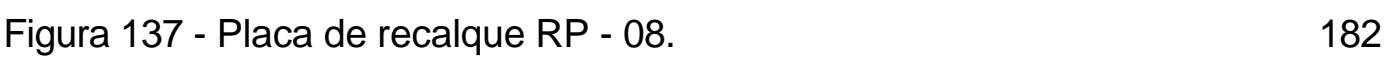

Figura 138 - Placa de recalque RP - 09.

Figura 139 - Placa de recalque RP - 10.

Figura 140 - Placa de recalque RP - 11.

Figura 141 - Placa de recalque RP - 12.

Figura 142 - Placa de recalque RP - $13 . \quad 187$

$\begin{array}{lr}\text { Figura } 143 \text { - Placa de recalque RP - } 14 . & 188\end{array}$

Figura 144 - Placa de recalque RP - 01.

Figura 145 - Placa de recalque RP - 02.

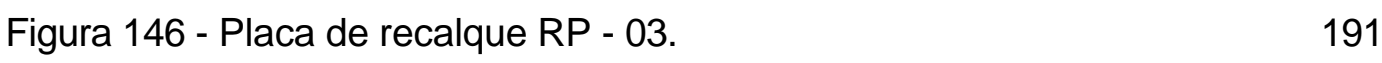

Figura 147 - Placa de recalque RP - 04.

Figura 148 - Placa de recalque RP - 27.

Figura 149 - Placa de recalque RP - 32.

Figura 150 - Placa de recalque RP - 16.

Figura 151 - Placa de recalque RP - 17.

Figura 152 - Placa de recalque RP - 18.

Figura 153 - Placa de recalque RP - $19 . \quad 198$

Figura 154 - Placa de recalque RP - 20.

Figura 155 - Placa de recalque RP - 21.

Figura 156 - Placa de recalque RP - 24.

Figura 157 - Placa de recalque RP - 28.

Figura 158 - Placa de recalque RP - 31. 


\section{Lista de tabelas}

Tabela 1 - Sensibilidade de argila (Skempton e Northey, 1952) 27

Tabela 2 - Fator tempo T (Houlsby \& Teh (1988)) 32

Tabela 3 - Razão entre as permeabilidades em argilas (Ladd et al, 1976) 33

Tabela 4 - Monitoramento em aterros 33

Tabela 5- Métodos de equilíbrio limite recomendados para análise de estabilidade (DNER-PRO 1998) 48

Tabela 6 - Fatores de Redução em Função do Tipo de Aplicação do Geossintético (Sieira, 2003)

Tabela 7 - Alturas do aterro e de sobrecargas no aterro. (Terratek, 2002) 64

Tabela 8 - Espessuras de argila mole 66

Tabela 9 - Peso específico dos grãos $\quad 72$

$\begin{array}{ll}\text { Tabela } 10 \text { - Valores de permeabilidade saturada } & 73\end{array}$

$\begin{array}{ll}\text { Tabela } 11 \text { - Parâmetros de resistência } & 76\end{array}$

Tabela 12 - Profundidade máxima dos ensaios $\quad 81$

Tabela 13 - Valores de permeabilidade in-situ da camada drenante 82

Tabela 14 - Observações sobre os ensaios de palheta descartados 93

Tabela 15 - Sensibilidade de argilas (Skempton e Northey, 1952) 97

Tabela 16 - Valores de $\mathrm{N}_{\mathrm{kt}}$ para a área C 103

Tabela 17 - Valores de Nkt para a área O 105

Tabela 18 - Valores de N $\Delta$ u e Nke nas áreas C e O 106

Tabela 19 - Profundidades dos ensaios de dissipação 111

Tabela 20 - Valores de $c_{v}$ e $c_{h}$ na argila mole pelo método de Houlsby e Teh

(1988) 113

Tabela 21 - Valores de cv e ch na argila siltosa pelo método de Houlsby e Teh (1998)

Tabela 22 - Placas de recalque instaladas na área L. 118

Tabela 23 - Coeficientes de adensamento para área L. 121

Tabela 24 - Placas de recalque instaladas na área C. 121

Tabela 25 - Placas de recalque instaladas na área O. 122

Tabela 26 - Coeficientes de adensamento para área C. 125

Tabela 27 - Coeficientes de adensamento para área O. 125

Tabela 28 - Fatores de segurança para área $L \quad 138$

Tabela 29 - Fatores de segurança para a área C 139 
Tabela 30 - Fatores de segurança para área $\mathrm{O}$

Tabela 31 - Resultados das análises químicas

Tabela 32 - Resultados dos ensaios CIU apresentados pela Tecnosolo 152

Tabela 33 - Resultados dos ensaios UU apresentados pela Tecnosolo 153 


\section{LISTA DE SÍMBOLOS}

$a_{v} \quad$ Coeficiente de compressibilidade

c' Intercepto da envoltória de resistência $\tau$ vs. $\sigma$

$\mathrm{C}_{\mathrm{c}} \quad$ Índice de compressão virgem

$\mathrm{C}_{\mathrm{h}} \quad$ Coeficiente de adensamento horizontal

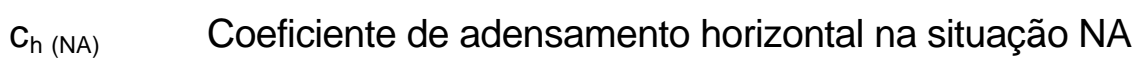

C I I Indice de recompressão

$\mathrm{C}_{\mathrm{r}} \quad$ Coeficiente de adensamento radial

$\mathrm{C}_{\mathrm{s}} \quad$ Índice de expansão

$\mathrm{C}_{\mathrm{u}} \quad$ Coesão não drenada

$\mathrm{C}_{\mathrm{V}} \quad$ Coeficiente de adensamento vertical

$\mathrm{C}_{\alpha} \quad$ Coeficiente de compressão secundária

D Módulo oedométrico ou confinado

d Profundidade do dreno

E Módulo de Young

e Índice de vazios

$E_{50} \quad$ Módulo de Young referente ao ponto $50 \%$ de $q_{f}$

$\mathrm{E}_{\mathrm{D}} \quad$ Módulo dilatométrico

$\mathrm{e}_{\mathrm{f}} \quad$ Índice de vazios final

$\mathrm{e}_{\mathrm{O}} \quad$ Índice de vazios inicial

$E_{u} \quad$ Módulo de Young não drenado

$\mathrm{E}_{\mathrm{u} 50} \quad$ Módulo de Young não drenado referente ao ponto $50 \%$ de $\mathrm{q}_{\mathrm{f}}$

$f(n) \quad$ Função da razão entre o diâmetro de influência do dreno e seu diâmetro efetivo

$\mathrm{f}_{\mathrm{amb}} \quad$ Fator de redução devido à danos ambientais

$\mathrm{f}_{\mathrm{dm}} \quad$ Fator de redução devido à danos mecânicos

$\mathrm{f}_{\mathrm{s}} \quad$ Atrito lateral

$\mathrm{f}_{\mathrm{t}} \quad$ Atrito lateral corrigido

G Módulo cisalhante

$\mathrm{G}_{\mathrm{s}} \quad$ Densidade relativa real dos grãos

$\mathrm{H} \quad$ Horizontal

$\mathrm{H}_{0} \quad$ Espessura inicial da camada 


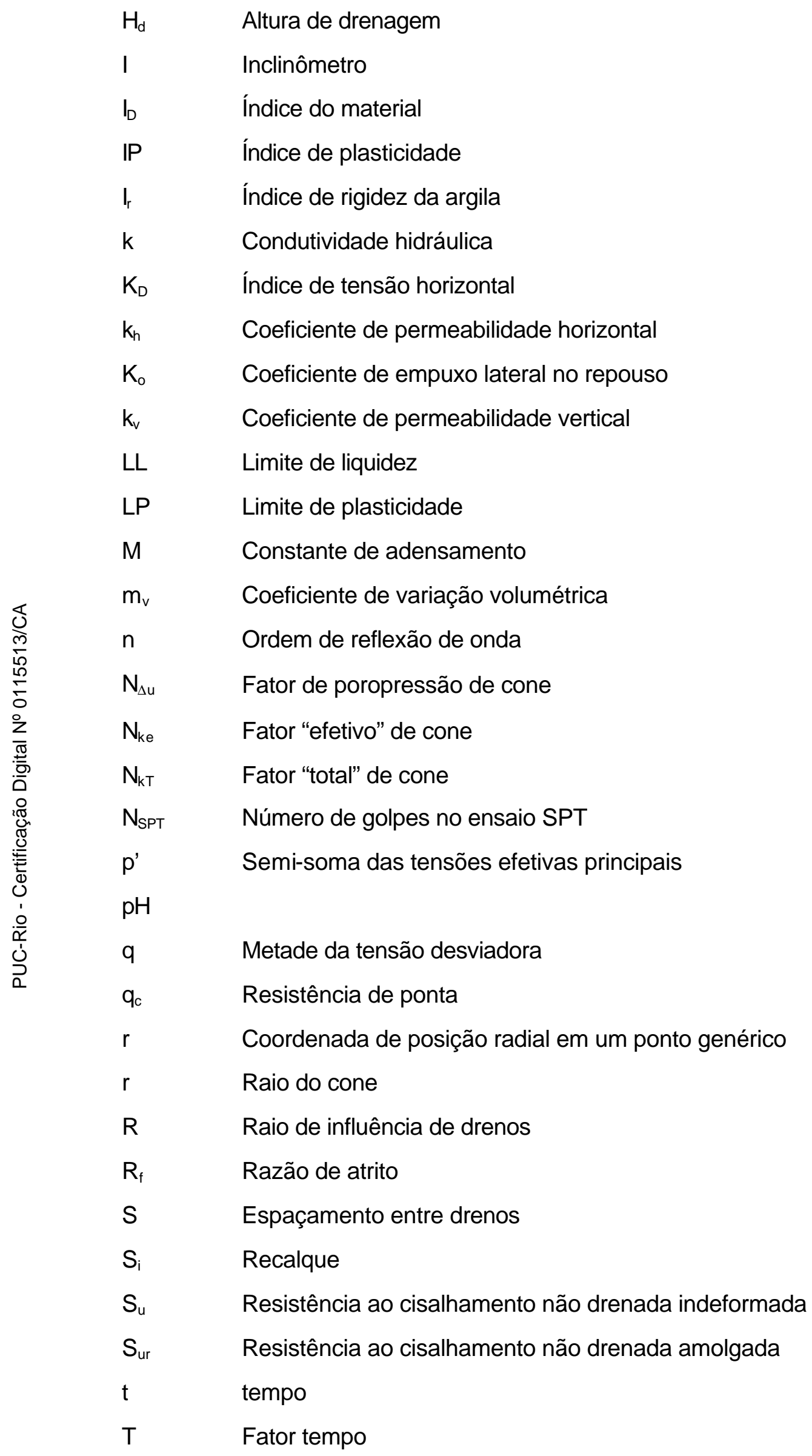


$\mathrm{T}_{50} \quad$ Tempo referente à $50 \%$ da dissipação do excesso de poropressão

$\mathrm{T}_{\mathrm{h}} \quad$ Fator tempo horizontal

$\mathrm{T}_{\text {projeto }}$ Resistência à tração de geossintéticos em projeto

$\mathrm{T}_{\mathrm{r}} \quad$ Fator tempo radial

$\mathrm{T}_{\text {ref }} \quad$ Resistência de referência à tração de geossintéticos

u Poropressão

U Porcentagem média de adensamento

$u_{b} \quad$ Poropressão na base

$U_{h} \quad$ Porcentagem média de adensamento devido à drenagem horizontal

$\mathrm{u}_{0} \quad$ Pressão hidrostática

$\bigcup_{v} \quad$ Porcentagem média de adensamento devido à drenagem vertical

$U_{v, n} \quad$ Porcentagem média de adensamento devido à drenagem combinada vertical e horizontal

V Vertical

w Teor de umidade

$w_{f} \quad$ Teor de umidade final

$\mathrm{w}_{\mathrm{O}} \quad$ Teor de umidade natural

z Profundidade

$\Delta \mathrm{h} \quad$ Variação de altura

$\Delta \mathrm{u} \quad$ Variação de poropressão

$\Delta \mathrm{e} \quad$ Variação do índice de vazios

$\Delta \mathrm{t} \quad$ Variação de tempo

$\Delta_{\mathrm{uf}} \quad$ Variação de poropressão na ruptura

$\Delta_{z} \quad$ Acréscimo de tensão vertical

$\Delta \sigma \quad$ Variação de tensões

$\Delta \sigma_{v}^{\prime} \quad$ Variação de tensão efetiva vertical

$\Delta \sigma_{d} \quad$ Variação de tensão desviadora

$\alpha^{\prime} \quad$ Inclinação da envoltória $p_{f}^{\prime}$ vs. $q_{f}$ (Lambe, 1967)

$\Delta \varepsilon_{\mathrm{a}} \quad$ Variação da deformação vertical

$\varepsilon_{\mathrm{f}} \quad$ Deformação axial na ruptura

$\varepsilon_{\mathrm{vol}} \quad$ Deformação volumétrica

$\phi^{\prime} \quad$ Ângulo de atrito efetivo 


\begin{tabular}{|c|c|c|}
\hline & $\gamma_{d}$ & Peso específico seco \\
\hline & $\gamma_{s}$ & Peso específico dos grãos \\
\hline & $\gamma_{\mathrm{t}}$ & Peso específico total \\
\hline & $\gamma_{w}$ & Peso específico da água \\
\hline & $v$ & Coeficiente de Poisson \\
\hline & $\rho$ & Recalque \\
\hline & $\rho_{\text {tempo }}$ & Recalque no tempo \\
\hline & $\rho_{\text {total }}$ & Recalque total \\
\hline & $\sigma_{c}^{\prime}$ & Tensão efetiva confinante \\
\hline & $\sigma_{v}^{\prime}$ & Tensão efetiva vertical \\
\hline & $\sigma_{v m}^{\prime}$ & Tensão de pré-adensamento \\
\hline & $\sigma_{\text {vo }}^{\prime}$ & Tensão efetiva vertical inicial \\
\hline & $\sigma$ & Tensão total \\
\hline & $\sigma_{\mathrm{a}}$ & Tensão axial \\
\hline 5 & $\sigma_{\mathrm{c}}$ & Tensão confinante \\
\hline 㕸 & $\sigma_{d}$ & Tensão desviadora \\
\hline 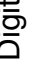 & $\sigma_{v}$ & Tensão total vertical \\
\hline דి & $\sigma_{\mathrm{v} 1}$ & Tensão total vertical no tempo inicial \\
\hline 5 & $\sigma_{\mathrm{v} 2}$ & Tensão total vertical no tempo final \\
\hline & $\sigma_{\mathrm{vo}}$ & Tensão total vertical inicial ou no campo \\
\hline & $\tau$ & Tensão cisalhante \\
\hline & $\sigma_{1}$ & Tensão principal maior \\
\hline & $\sigma_{3}$ & Tensão principal menor \\
\hline & ABNT & Associação brasileira de normas técnicas \\
\hline & AISF & Aeroporto Internacional Salgado Filho, RS \\
\hline & ASTM & "American society for testing materials" \\
\hline & CID & Consolidado isotropicamente drenado \\
\hline & CIU & Consolidado isotropicamente não drenado \\
\hline & CIU & Consolidado isotropicamente não drenado com medida de poropressão \\
\hline & $\mathrm{CK}_{0} \mathrm{U}$ & Consolidado na linha $\mathrm{K}_{\mathrm{o}}$ - não drenado \\
\hline & Coppe & $\begin{array}{l}\text { Instituto Alberto Luiz Coimbra de Pós-Graduação e Pesquisa de } \\
\text { Engenharia }\end{array}$ \\
\hline
\end{tabular}


CP Piezômetro de Casagrande

CPTU "Cone penetration test" com medida de poropressão

CRS "Constant rate of strain"

DNER Departamento Nacional de Estradas de Rodagem

ETE Estação de tratamento de esgoto

FS Fator de Segurança

IPR Instituto de Pesquisas Rodoviárias

NBR Norma brasileira

OCR Razão de pré-adensamento ("Over Consolidation Ratio")

PR Placas de recalque

Reduc Refinaria Duque de Caxias

Senac Serviço Nacional de Aprendizagem Comercial

Sesc Serviço Social do Comércio

SPT "Standart penetration test"

SPT "Standart penetration test" com medida de $S_{u}$

VWP Piezômetro de corda vibrante 